\title{
How Does Technology-Enabled Active Learning Affect Undergraduate Students' Understanding of Electromagnetism Concepts?
}

\author{
Yehudit Judy Dori \\ Department of Education in Technology and Science \\ Technion-Israel Institute of Technology \\ John Belcher \\ Department of Physics and Center for Educational Computing Initiatives \\ Massachusetts Institute of Technology
}

Educational technology supports meaningful learning and enables the presentation of spatial and dynamic images, which portray relationships among complex concepts. The Technology-Enabled Active Learning (TEAL) Project at the Massachusetts Institute of Technology (MIT) involves media-rich software for simulation and visualization in freshman physics carried out in a specially redesigned classroom to facilitate group interaction. These technology-based learning materials are especially useful in electromagnetism to help students conceptualize phenomena and processes. This study analyzes the effects of the unique learning environment of the TEAL project on students' cognitive and affective outcomes. The assessment of the project included examining students' conceptual understanding before and after studying electromagnetism in a media-rich environment. We also investigated the effect of this environment on students' preferences regarding the various teaching methods. As part of the project, we developed pre- and posttests consisting of conceptual questions from standardized tests, as well as questions designed to assess the effect of visualizations and experiments. The research population consisted of 811 undergraduate students. It consisted of a small- and a large-scale experimental groups and a control group. TEAL students improved their conceptual understanding

Correspondence and requests for reprints should be sent to Yehudit Judy Dori, Department of Education in Technology and Science, Technion-Israel Institute of Technology, Haifa 32000, Israel. E-mail: yjdori@tx.technion.ac.il 
of the subject matter to a significantly higher extent than their control group peers. A majority of the students in the small-scale experiment noted that they would recommend the TEAL course to fellow students, indicating the benefits of interactivity, visualization, and hands-on experiments, which the technology helped enable. In the large-scale implementation students expressed both positive and negative attitudes in the course survey.

“Tomorrow's citizens, tomorrow's leaders, tomorrow's experts are sitting in today's college classrooms. Are they learning what they need to know? Are faculty using teaching methods that prepare them for future roles?" (Huba \& Fredd, 2000, p. 2).

The Technology-Enabled Active Learning (TEAL) project described in this article specifically addresses this question. Although targeted at physics undergraduate large-scale courses, the TEAL project may serve as a model for science and technology courses in higher education. Introductory undergraduate physics courses are fundamental underpinnings of any science or engineering education. Scientists at the academy have a double commitment to both research and education but there is a constant gap between the state-of-the-art in physics research on the one hand and the practice of teaching these core undergraduate science courses on the other (Bevilacqua \& Giannetto, 1998). This applies both to the subject matter taught in freshmen basic courses and the teaching methods that are usually practiced in large lecture halls.

The subject matter and many of the concepts in the introductory undergraduate physics courses are abstract and cognitively demanding. Moreover, the underlying mathematical complexity can quickly overwhelm students' intuition. Consequently these courses are difficult for students to master. The situation is compounded by typical undergraduate teaching methods, which involve professors lecturing in front of large audiences of hundreds of students. Indeed, the traditional and still most prevalent means of teaching the basic science courses are lectures, which closely follow material in textbooks. Settings of this nature diminish the opportunity to develop free, spontaneous exchange of ideas and do not foster active learning. This passive setting may sometimes be accompanied by laboratories with experiments designed to rediscover the laws of nature, which alleviates the problem to a certain extent, but certainly does not solve it.

As excellent as an instructor may be, teaching freshman courses in a large lecture hall with over 300 students listening to him or her, is based on the assumption that the instructor can "pour out" knowledge from his or her vast reservoir into the empty glasses of the students' minds. The students are required only to be careful enough and not spill any of this information. If this were true, students at MIT would not fail these large required classes. The high failure rates in these courses at MIT, approaching 15\%, and the low attendance in lectures at the end of the term, less than $50 \%$, suggest that there is a basic flaw in this model of instruction. 
Motivated by a desire to change the prevalent passive teaching mode and to involve students in active learning enhanced by technology, we have introduced a significant reform in freshman physics education at MIT. Our approach is designed to help students visualize, hypothesize, and improve their intuition about conceptual models of electromagnetic phenomena. The reform is centered on an "active learning" approach, which combines a collaborative, hands-on environment with the use of desktop experiments, Web-based assignments, and educational technology. To provide an adequate learning environment, a tailor-made classroom, the TEAL studio space, was designed. As Figure 1 shows, the classroom has neither front nor back. Rather, a lectern, from which the instructor can control the technology in the classroom, stands in the middle of the classroom surrounded by round tables for the students. From this point on, depending on the context, we refer to the electricity and magnetism (E\&M) course which was carried out in the specially designed studio space either as the E\&M course in the TEAL format or simply the TEAL project.

This article first discusses the social constructivist theory, active learning, physics education reforms, and educational technology as a basis for active learning. It then describes the unique learning environment of the TEAL project carried out in a specially redesigned classroom to facilitate group interaction. Aiming at enhancing conceptual understanding of electromagnetism phenomena, the TEAL project is designed to actively engage students in the learning process, using technology-enabled methods as appropriate. We analyze the effect of the TEAL project on students' cognitive and affective outcomes. We present findings showing that TEAL students improved their conceptual understanding of the subject

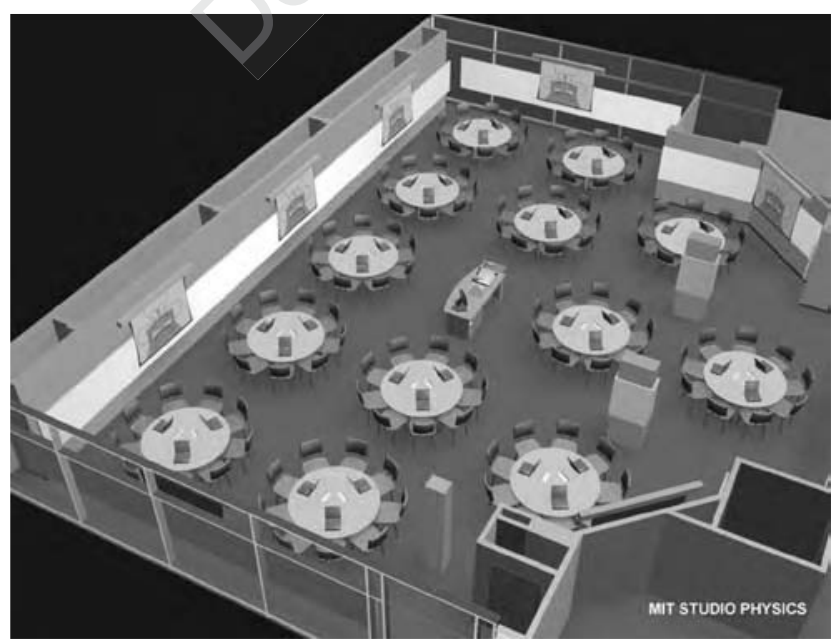

FIGURE 1 A 3D model of the d'Arbeloff Studio classroom - the TEAL space. 
matter to a significantly higher extent than their control group peers. With respect to the affective domain, we cite students indicating the benefits of interactivity, visualization, and hands-on experiments. These findings, along with research limitations, are finally discussed in the context of social constructivism.

\section{THEORETICAL BACKGROUND}

The TEAL project is founded on three elements: educational theory, the subject matter, and the educational technology. We start this article with a presentation of constructivist theory, which provides a solid pedagogical basis for our course design. We proceed with a discussion of the problematic issues involved in conceptualizing electromagnetic field theory, which is the focus of the TEAL project. We end with a presentation of the role of educational technology and options that such technologies make available to science educators and to students alike.

\section{Social Constructivist Theory}

Constructivist theory puts the construction of knowledge in one's mind as the centerpiece of the educational effort. A basic assumption of teaching according to the constructivist learning approach is that knowledge cannot simply be transmitted from teachers to learners: learners must be engaged in constructing their own knowledge (von Glaserfeld, 1989). The outcome of instruction using a simplistic transmission model of teaching is often rote learning, leading to inert knowledge (Bruer, 1993; Perkins, 1992). Constructivist instruction, however, at least potentially results in meaningful learning and understanding. The learner is encouraged to create the knowledge in her or his mind. In so doing, the learner becomes the "owner" of the knowledge. Such ownership enables the learner to understand the knowledge in an intimate way that cannot be achieved by mere memorization. In some cases, the information gathered by the constructivist learner fits nicely into her or his mental framework and poses no problem. Other cases, in which the mental framework is incapable of handling this new information, require that the learner take an active role in the learning process so as to adjust her or his cognitive framework to accommodate the new information. This way, the constructivist approach fosters meaningful learning and deep understanding of physical phenomena.

Social constructivism has a somewhat different flavor than the original conception of constructivism. From the perspective of constructivism, learning takes place within a person's mind. Learners "learn by doing" to accommodate new knowledge through experiencing and assimilating newly acquired knowledge into their current conceptual understanding (Inhelder \& Piaget, 1958). Social constructivist ideas enable one to investigate and support the notion that knowl- 
edge is not the property of individuals; rather it happens in a group setting, where knowledge is distributed and shared. The role of social interaction is central in teaching and learning science and in studying the world. (Duit \& Treagust, 1998; Vygotsky, 1963). Peers help each other by offering alternatives and sustaining reasoning activities, and individuals benefit from this interaction by integrating knowledge from peers and the environment (Vygotsky, 1978).

In discussing social constructivism, Duschl and Hamilton (1998) explained that recent research has focused on the social circumstances of cognitive activities, such as communities of scientists and learners. The shift from a focus on individuals to a focus on members of the community has implications for science teaching in general and on conceptual change (Strike \& Posner, 1985) in particular. Shifting from the education of individual scientists or learners to communities of scientists or groups of students requires a fundamental change in the environments we construct for learning science and in what we ask our students to do in those environments. Hence, carefully constructed learning environments can facilitate students' understanding of concepts in science.

Duit and Treagust (1998) noted that little research knowledge is available on the relationship between social constructivist views of learning and the learning environments that support conceptual change. Such a change mandates a parallel change in assessment approaches. As Bybee and Ben-Zvi (1998) indicated, science educators have focused primarily on content and secondarily on instruction, leaving assessment and implementations to others or completely ignoring them. These authors recommend incorporating assessment as part of the science curriculum and instruction. They acknowledge that this places additional burden on curriculum developers but they claim that the challenge is worth the effort, as the resulting program is complete, coherent, and consistent.

Salomon and Perkins (1998) distinguished several meanings to social learning, including active social mediation of individual learning - a person or team helping an individual to learn, social mediation as participatory knowledge construction — generating learning products through joint group activities, and social mediation by cultural scaffolding - technological tools and information sources that serve the learning by challenging the learner (Salomon, Perkins, \& Globerson, 1991).

Active learning often goes hand in hand with constructivist ideas, and was initially promoted by Dewey (1924). Emphasis is placed less on transmitting information and more on developing student's skills (Keyser, 2000). Active learning environments encourage students to engage in solving problems, sharing ideas, giving feedback, and teaching each other (Johnson, Johnson, \& Smith, 1998). The thinking required while attending a lecture is low-level comprehension of factual knowledge that goes from the ear to the writing hand (Towns \& Grant, 1997). Johnson et al. (1998) pointed out that students' attention to what the instructor was saying decreased as the lecture proceeded. Integrating active learning strategies as part of the formal learning sessions can advance students' learning, and although 
schools are undergoing cultural change toward more active learning, there are many obstacles yet to be overcome (Niemi, 2002).

The TEAL environment was designed to support social interactions, encourage students' active learning and interest, and create a classroom climate that fosters conceptual change. In this article, we refer to conceptual change as a change from intuitive ideas toward accepted scientific ideas that are more intelligible (Strike \& Posner, 1985). We encouraged explanations of students to their peers to reformulate one's initial ideas toward conceptual change (Chi, 1992; Slotta \& Chi, 1996) by enabling TEAL students to gain experience and become more sophisticated in choosing which ideas to select and apply for problems with which they are presented. We also integrated several assessment elements throughout the course, which added value to such diverse factors as student team heterogeneity and student preparedness and understanding.

\section{Physics Education Reforms and Electromagnetism as a Case in Point}

Until the early 1990's, most physics instructors were largely unaware of the outcomes of research in physics education (Laws, Rosborough \& Poodry, 1999). During the past 15 years, a number of physics curricula have been developed that utilize educational research outcomes. The college-level physics curricula include-Physics by Inquiry and Tutorials in Introductory Physics (McDermott, 1991; McDermott \& Shaffer, 2002), Workshop Physics (Laws, 1991),_-Tools for Scientific Thinking (Thornton \& Sokoloff, 1990), RealTime Physics (Sokoloff, Thornton \& Laws, 1999),-_Matter \& Interaction (Chabay \& Sherwood, 1996; 2000), - Studio Physics (Cummings, Marx, Thornton \& Kuhl, 1999), and—SCALE-UP (Beichner, 2002). The common thread in all these curricula is that they emphasize elements of active learning and conceptual understanding that build on making predictions, and observing and discussing the outcomes with peers. Hake (1998) showed that the learning gains in undergraduate physics are almost double when active learning is involved. However, many of the students resent having to "teach themselves" and prefer lectures. Instructors often need to face the challenge of switching from traditional modes to creative instructional strategies and experience difficulties in this process of breaking away from ways in which the instructors had been taught (Laws, 1991).

Classical Newtonian mechanics has traditionally been the first subject taught in both high school and undergraduate physics courses. Therefore, most of the new educational projects and curricula, as well as physics education research and the standard tests, focused on mechanics. The subject of electromagnetism, however, has received less attention as far as new teaching methods are concerned (Bagno \& Eylon, 1997; Eylon \& Ganiel, 1990; Maloney, O’Kuma, Hieggelke \& Van Heuvelen, 2001; Thacker, Ganiel \& Boys, 1999). 
Scientists in the first half of the 19th century struggled to develop the electromagnetic field model and to conceptualize electromagnetic phenomena. It should come as no surprise that undergraduate students encounter serious difficulties when confronted with modern electromagnetic theory. Faraday developed an explanation of electromagnetism by thinking in terms of lines of force that spread throughout space. There was much criticism of his field approach, however, with many scientists preferring to think in terms of "action at a distance." Later in that century, Maxwell formulated Faraday's field model mathematically, and predicted that light was an electromagnetic phenomena. When Hertz confirmed this prediction experimentally at the end of the 19th century, Maxwell's model of electromagnetic fields was established as the reigning paradigm (Furio \& Guisasola, 1998).

Many studies have documented students' conceptual difficulties in the domain of electricity and magnetism (Bagno \& Eylon, 1997). While studying electricity, students tend to confuse current, voltage, energy and power. They often misinterpret schematic representations (McDermott \& Shaffer, 1992), do not relate macro and micro relationships in electric circuits (Chabay \& Sherwood, 1995), and are unable to link electrostatics and electrodynamics (Eylon \& Ganiel, 1990). While studying Coulomb's Law, students do not apply Newton's Third Law to electric point charge situations. They seem to believe that larger objects exert larger forces than smaller ones regardless of the charges they carry and the distance between them (Maloney et al., 2001).

The problem with comprehending magnetism, which has been studied to much a lesser extent than electricity, seems to be even more pronounced due to the fact that humans are simply not equipped with sensors to gauge magnetism. Although electricity can be indirectly observed (e.g., as light generated by current flowing through light bulbs), or felt by electric shocks, there is almost no sensual indication of magnetic fields. Maloney and colleagues (2001) characterized the following difficulties related to understanding magnetic forces: Students confuse electric and magnetic forces and do not consider Newton's Third Law to be applicable in magnetism either. They also expect a magnetic force to be present whenever an electric charge is placed in a magnetic field, regardless of whether the charge has a velocity with a component perpendicular to the magnetic field direction.

\section{Imagery in Physics}

Imagery, a universal language of the mind, uses human imagination to think in pictures, sounds, smells, tastes, or touch sensations (Manhart Barrett, 2003). Unlike mechanical phenomena, such as motion, acceleration, and impetus, which can be sensed visually, and sometimes also vocally and through touching, electromagnetism is in a realm of physics that is not covered by any one of the five human senses. This is the major reason for difficulties encountered by students of all ages when trying to make electromagnetic concepts concrete. Our contention is that visual 
imagery can help make the abstract concepts encountered in electromagnetism more concrete.

As an example of the use of visual imagery in science, consider Einstein, whose imagination helped shape 20th century science. Einstein noted that "Imagination is more important than knowledge. Knowledge is limited. Imagination encircles the world" (Einstein as noted by Viereck, 1929). Many of Einstein's ideas for his theories appeared to him in dreams but he also used visualization in waking life to develop his ideas, views, and theories. Miller (1984) has discussed the vital role of imagery in the creation of 20th century modern physics, accounting for scientists whose discoveries came as a "lightening flash" (p. 301).

Around 1925, behaviorism was on the rise and visualization of the atom gave way to more mathematical treatments of it. For example, instead of the unobservable electron orbits derived from visual thought experiments, the quantum properties of the atom were measured by spectral lines that serve as the atom's signature (Miller, 1984). This departure from imagery and visualization to pure mathematics came at the price of making physical phenomena abstract, rendering them very difficult for any exposition based on sensory arguments. Students who are new to the topic of electromagnetism face great difficulties in grasping the subject using only mathematical equations, and the innate complexity of the underlying mathematics further obscures the physics. Maxwell (as quoted by Simpson, 1997, p. 55.) said that "In order ... to appreciate the requirements of the science [of electromagnetism], the student must make himself familiar with a considerable body of most intricate mathematics, the mere retention of which in the memory materially interferes with further progress."

Difficulties also arise for students new to the topic because the standard introductory approach does little to connect the dynamics of electromagnetism to the everyday experience of students. Because much of our learning is done by analogy, students have a hard time constructing conceptual models of the ways in which electromagnetic fields mediate the interactions of the charged objects that generate them. An approach to overcome these difficulties has been known since the time of Faraday, who originated the concept of fields (Belcher \& Olbert, 2003). Faraday was the first to understand that the topology of electromagnetic field lines is a guide to their dynamics. By trial and error, he deduced that electromagnetic field lines exert a tension parallel and a pressure perpendicular to themselves. Knowing the shape of field lines from his experiments, he was able to understand the dynamical effects of those fields based on simple analogies to strings and ropes (Cross, 1989; Hermann, 1989). Faraday's insight into the connection between shape and dynamics can be enhanced by visual imagery, in particular by the animation of field line motion (Belcher \& Bessette, 2001). Animation allows the student to gain insight into the way in which fields transmit forces, by watching how the motions of material objects evolve in time in response to those forces. Such animations enable the student to better make the intuitive connection between the stresses trans- 
mitted by electromagnetic fields and the forces transmitted by more prosaic means, for example, by rubber bands and strings.

In view of the difficulties that scientists and students encountered in understanding electromagnetism, the desirability of a new curriculum that involves active learning and modern educational technology is apparent.

\section{Educational Technology and Activity-Based Learning}

Educational technology can support meaningful learning and knowledge integration. Social construction of knowledge does not take place frequently enough in a traditional teacher-centered learning environment, where interaction emphasizes the role of the all-knowing teacher (Jonassen, Davidson, Collins, Campbell \& Haag, 1995; O’Malley, 1999). However, Clark (1994) emphasized that learning gains come from adequate instructional design theory and practice, which is as important as the medium used to deliver meaningful instruction. Used properly, educational technology fosters knowledge and concept representations that cater to a variety of learning styles (Jonassen et al. 1995). In the context of physics education, educational technology offers several types of tools, including micro-based laboratories (MBL) and dynamic model-building systems. Integrating these two types of tools enables students to switch between measuring and modeling, and to benefit from the resulting synergy (Beichner, 1994; Scheker, 1998; Thornton, 1992). MBL, which we refer to as desktop experiments, narrows the time gap between measuring and evaluating the data (Scheker, 1998), making it possible for students to see graphs generated in real time in response to experiments they carry out. Brasell (1987), for example, found that real-time graphing is crucial for students to relate graphical representations of velocity to observed motion. Thornton and Sokoloff (1990) found strong evidence for significantly improved learning and retention by students who used MBL materials compared to those taught in lecture. Desktop experiments provide for integration of data acquisition with tools for data analysis, modeling, and computations, enabling the student to use models as a bridge between the mathematical function that reproduces a result and the underlying physical concepts that give rise to such relationships (Scheker, 1998).

Spatial images (for example in simulations) preserve relationships among a complex set of ideas and play a central role in scientific creativity (Mathewson, 1999). Schank (1993/1994) argues for computer-designed scenarios to construct effective learning environments, although White (1993) makes the point for computer microworlds to allow students to construct models of natural systems. Jonassen, Carr and Yueh (1998) noted that technologies should serve as knowledge construction tools that students learn with rather than support learning by attempting to instruct the learners. 
Incorporating physics into an integrated freshman engineering class, Beichner et al. (1999) found that a highly collaborative, technology-rich, activity-based learning environment led to the better performance of experimental students with respect to their cohorts in demographically matched traditional classes, often by a wide margin. Student satisfaction and confidence, as well as their retention rates, were remarkably high.

These positive experiences with collaborative learning, educational technologies, and the possibilities they offer motivated us to implement an active learning environment. In this environment, small teams of students use computer-based dynamic visualization and computer-based laboratory experiments as the primary aids for providing insight into the complicated dynamics exhibited by electromagnetic phenomena.

\section{TEAL PROJECT OBJECTIVES AND SETTING}

To realize our vision of the TEAL project, we have initiated a complete change in the way undergraduate physics courses are taught at MIT. The first course we decided to undertake is electromagnetism (E\&M), because in this course students have the most difficulty in conceptualizing and visualizing the physical concepts - specifically phenomena related to the electromagnetic field.

\section{The TEAL Project}

The Technology Enabled Active Learning (TEAL/Studio, or TEAL for short) project is a studio format course designed to accommodate large enrollment in freshman physics at MIT. It is aimed at serving as a model for a new format of undergraduate science courses for large groups of students at MIT and possibly elsewhere. The TEAL/Studio environment is a carefully thought-out blend of mini lectures, recitations, and hands-on laboratory experience, which are merged into a technologically and collaboratively rich experience for students (primarily incoming freshmen). Patterned in a number of ways after the Studio Physics effort of RPI (Cummings et al., 1999) and the SCALE-UP effort of NCSU (Beichner, 2002), TEAL improves upon these efforts by incorporating a variety of visualizations, both passive and active. These visualizations enable students to develop intuition about various electromagnetic phenomena by making the unseen seen in game playing and experimentation. Although a number of stand-alone visualizations have been developed for physics undergraduate courses, TEAL is innovative in that it applies state-of-the-art visualization technologies to transform the main E\&M topics of this introductory course from abstract to concrete (Dori et al., 2003). In the context of the studio format, TEAL is a step forward with respect to previous efforts in that (a) it can accommodate 117 students at a time and (b) all the 
MIT undergraduate students are obliged to take the E\&M course in the TEAL format (except for an advanced version for students with excellent mathematical backgrounds who are interested in majoring in physics).

\section{The Objectives of the TEAL Project}

The first implementation of the TEAL/Studio project on a large scale is for electromagnetism; a mechanics course in this format is currently being taught on a small-scale. Following the social constructivist guidelines and employing educational technology, the objectives of the Project are to:

1. Transform the way physics is taught at large enrollment physics classes at MIT.

2. Decrease failure rates in these courses.

3. Create an engaging and technologically enabled active learning environment.

4. Move away from a passive lecture/recitation format.

5. Increase students' conceptual and analytical understanding of the nature and dynamics of electromagnetic fields and phenomena.

6. Foster students' visualization skills.

The project was scheduled to take 5 years to reach full implementation, from Fall 2000 until Spring 2005.

\section{The Setting of the TEAL Project}

The study we report on here was conducted during the Fall 2001 (experimental), Spring 2002 (control), and Spring 2003 (experimental) semesters. A pilot study had been conducted when the space and the technology were both still under development during Fall 2000 semester. The course was then taught in a lecture/recitation format with peer interaction in lecture and desktop experiments in some recitations. Recognizing the importance of assessment throughout the lifecycle of the project, we designed the pilot study such that it enabled us to establish a baseline for assessing the entire TEAL/Studio project.

In Fall 2001, the physical infrastructure was in place, including a newly renovated studio physics classroom. The setting included 13 round tables with 9 students seated around each table and working in teams of three on one laptop per team (see Figure 2). A significant portion of the newly developed learning materials and visualization aids were also ready for use in Fall 2001, and the rest of the learning materials and visualizations were being added gradually throughout Spring 2003. A typical class is comprised of mini lectures scattered throughout the class, separated by periods in which students are engaged in hands-on desktop ex- 


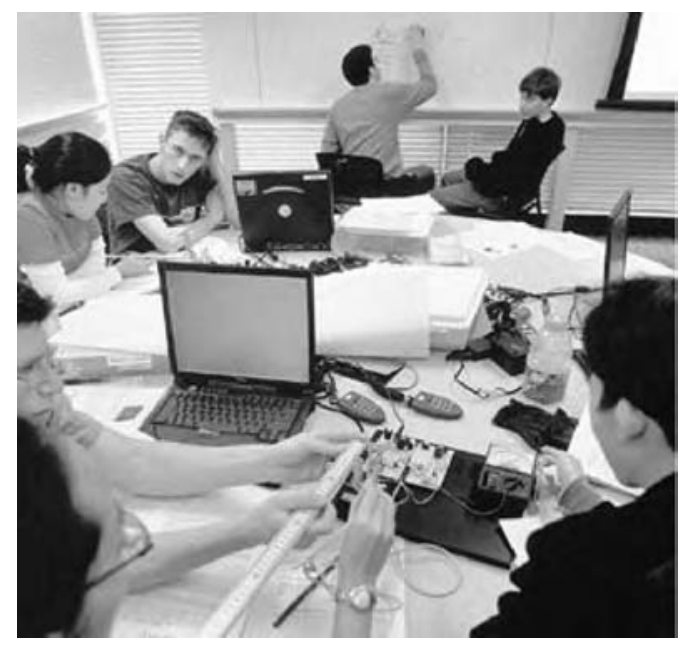

FIGURE 2 The TEAL classroom in action.

periments, visualizations, problem solving, and peer discussions. It is worth noting that in Fall 2001 the course was taught by two instructors, each teaching about 90 students. One of these instructors (the second author) initiated and led the TEAL project, and the other was part of the TEAL development team. The Spring 2003 course was taught by six new instructors, none of whom had been previously involved in TEAL, and a few of those instructors were not comfortable with using TEAL's media-rich environment.

Collaboration in the TEAL project is a major theme, and it has been employed in both teaching and learning. Instructor collaboration has involved working in teams that include physicists, who are the domain experts, science educators, who design the course format and assessment, and educational technology professionals, who implement the visualization and computer-based laboratory activities. Student collaboration entails working in small and larger heterogeneous groups, consisting of three to nine students, constructing knowledge with one another by asking questions, explaining ideas, and carrying out experiments.

\section{Hands-On Experiments, Visualizations, and Technology-Enabled Question Posing}

The laboratory hands-on experiments that students carry out as part of the course are of exploratory nature and often accompanied by advanced real-time data collection and processing instrumentation, also referred to as desktop experiments or real-time physics laboratories (Sokoloff et al., 1999). As Figures 3 through 5 dem- 


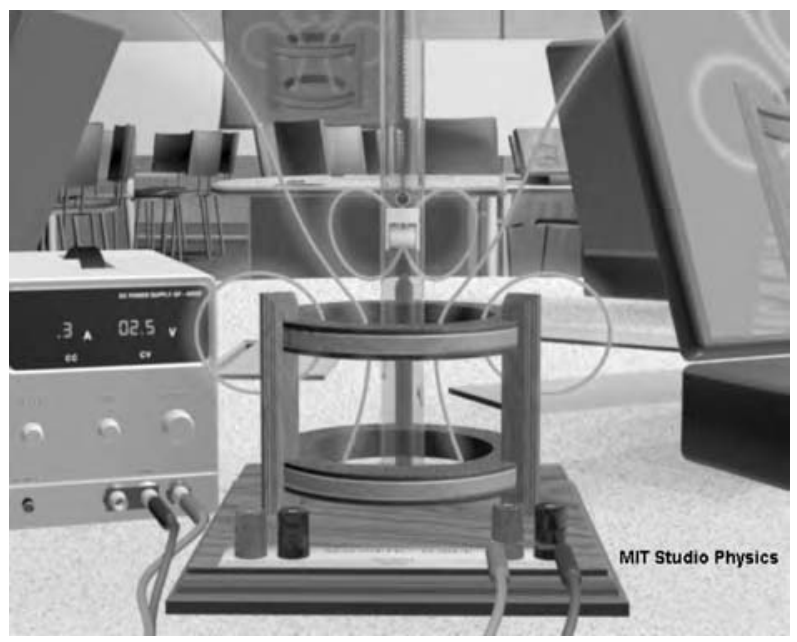

FIGURE 3 The TeachSpin ${ }^{\circledR}$ magnetic force experiment and the corresponding visualization.

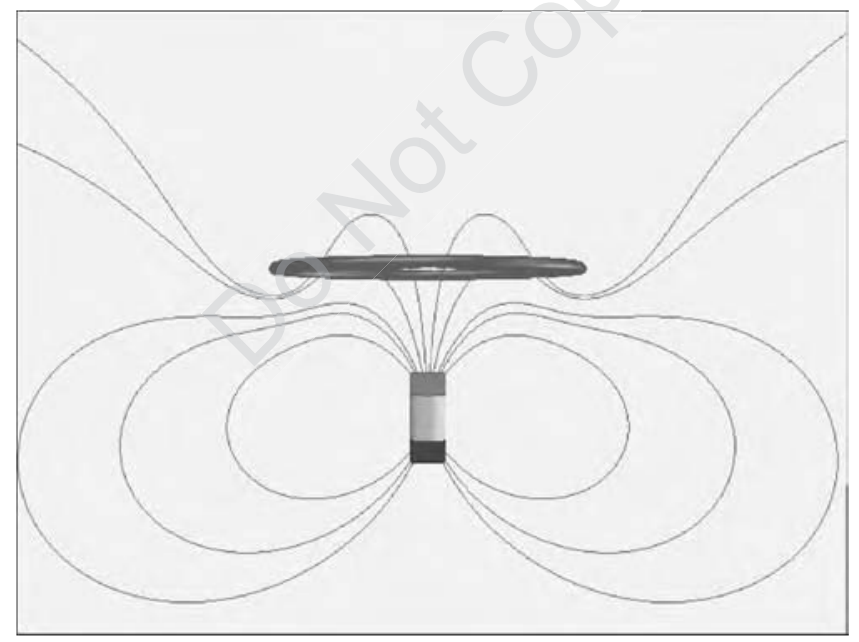

FIGURE 4 A Java applet showing a conducting non-magnetic loop of wire falling under gravity past a fixed permanent magnet.

onstrate, the experiments are complemented by engaging 2D and 3D visualizations and simulations of the phenomena under study (Belcher \& Bessette, 2001; Belcher, Olbert \& Bessette, 1999; Belcher and Olbert, 2003). The visualizations allow students to make abstract ideas concrete. More specifically, students gain insight into such concepts as how electromagnetic fields transmit forces by watching 


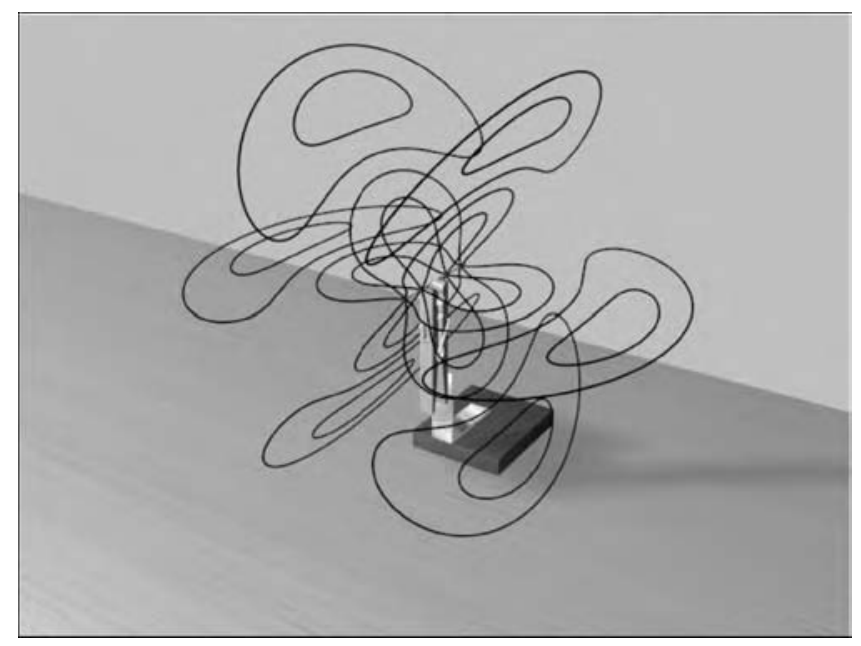

FIGURE 5 A visualization of microwave generator desktop experiment.

how the motions of objects evolve in time in response to those forces. Such animations allow students to develop intuition regarding connections between the forces transmitted by electromagnetic fields and more tangible forces, such as those exerted by rubber bands or strings.

For example, Figure 3 presents the TeachSpin ${ }^{\circledR}$ magnetic force experiment and its corresponding visualization. In one part of this experiment, students observe the force of repulsion between a permanent magnet hanging from a spring and a stationary current-carrying coil of wire. The corresponding visualization in Figure 3 gives them intuition for how this repulsion is transmitted by the magnetic field across the "empty space" between the coil and the magnet. The augmented-reality 3D model of the experiment includes the (normally invisible) magnetic field lines. The superposition of the magnetic field lines in the visualization of the experiment makes the linkage between the electric current and the magnetic field it generates concrete. The combination of this visualization with the hands-on experiment students carry out using real-life tangible hardware is an example of the unique nature of the TEAL project.

Figure 4 shows an example of an interactive simulation that corresponds to a Faraday's Law desktop experiment. In this desktop experiment, the student lets a loop of wire fall along the axis of a magnet and observes the resultant eddy current in the loop, as predicted by Faraday's Law. In the associated Java applet, the student can perform the same experiment "virtually" and "see" both the eddy current and the magnetic field it produces. The field of the eddy current is generated in accord with Lenz's Law- that is, the field is such as to try to keep the total magnetic flux through the wire loop from changing. 
In the simulation, the Java applet calculates the motion of the falling wire loop and also calculates and plots the magnetic field lines of both the magnet and the eddy current in the loop. Using sliders and text fields at the bottom of the screen, a student can change two parameters in the simulation. The first, "Resistance," is proportional to the resistance of the wire loop divided by its inductance, while the second, "Dipole Moment/Mass," is proportional to the dipole moment of the magnet divided by the square root of the mass of the magnet. Students are asked to lower the "Resistance" parameter while keeping the "Dipole Moment/Mass" parameter fixed, and vice versa. While watching this visualization with the various parameter values, the student is asked to respond to questions such as:

1. "Is there a way to get the wire loop to levitate above the fixed magnet forever? How?"

2. "Even if the resistance of the wire loop is zero, can you get the wire loop to fall past the magnet? How?"

3. "If you can do this, how can the magnetic flux through the wire loop stay constant as the loop falls infinitely far below the magnet?"

Questions such as these not only provide the students with insight into results of the desktop experiment that they performed, but also help them expand that insight to analogous experiments that they cannot do in class (for example, to the case of a wire loop with zero resistance).

Finally, Figure 5 shows a visualization of the antenna pattern around a quarter-wave antenna which accompanies a microwave generator desktop experiment students do in class. This desktop experiment was originally developed by King, Morrison, Morrison, and Pine (1992). As part of the experiment, students measure the angular distribution and polarization of the electric field generated by the antenna. The associated visualization shows a faithful 3D model of the quarter-wave antenna in the desktop experiment, as well as the electric field pattern around that antenna. This visualization helps them understand why this electric dipole radiation pattern has the shape and polarization it does, as well as interpret the measurements they make of the "invisible" electric field radiation around the antenna. To demonstrate a round table discourse in class while this microwave generator desktop experiment and its associated visualizations were conducted, the Findings section includes part of a transcript taken during that session. Additional examples of the TEAL visualizations and simulations can be found at the TEAL website. See http://web.mit.edu/8.02t/www/802TEAL3D/teal_tour.htm.

Two additional technology-enabled and one traditional question posing elements in the course which foster conceptual learning are (a) individual on-line home assignments twice a week, (b) an in-class personal response system (PRS), and (c) weekly written problems. Students are required to submit on-line answers to questions that are aimed at preparing them for the upcoming class, or others that relate to 
the experiments or visualizations conducted during the class. The correct answers to these home assignments are posted on the course Website immediately after the submission date. Using the PRS and following the idea of Mazur (1997), each student is requested to respond in-class in real time to multiple choice questions asked by the teacher as part of the mini lecture. The response distribution is presented on the classroom screens as a bar graph and if it appears that there is no clear consensus on the correct answer, the teacher asks the small groups of three students to conduct a peer discussion, convince each other, and try to come up with an agreed-upon answer. The students are again asked to respond to the same question and, usually at that point, the PRS-generated distribution shows that as a result of this peer discussion students have a better understanding of the question and agree on the correct answer. The written problems included individual problem sets given as home assignments once a week and analytical problems solved in class.

\section{RESEARCH GOALS AND METHODOLOGY}

This study analyzes the effects of the TEAL project on students' social, cognitive, and affective outcomes. The research goals are:

1. In the social domain, to characterize student interactions while studying in small groups in the TEAL project;

2. In the cognitive domain, to assess students' conceptual change as a result of studying electromagnetism in the TEAL project; and

3. In the affective domain, to analyze students' attitudes towards the TEAL learning environment, and to study their preferences regarding the combination of various teaching methods.

To achieve these goals, our research methodology combines quantitative and qualitative methods and instruments. To characterize the social aspects of learning (the first research goal) we applied observations. The quantitative instruments were used primarily to support the second goal, namely to quantify the extent of change in students' concepts as a result of taking the E\&M course in the TEAL format, as opposed to doing so using the traditional teaching mode. Results in the cognitive domain are the primary focus of interest of stakeholders and decision makers in educational management. Because this research assessed students' achievements in a new setting in a demanding academic environment, quantitative results were required for accountability. To assess the affective domain (the third research goal), we used an open-ended survey and focus groups to ask the experimental students about their preferences of teaching methods in the TEAL environment. The findings of the surveys were analyzed both qualitatively and quantitatively. 


\section{Research Population}

The experiment involved two experimental groups and one control group. The first implementation of the TEAL project was in a freshman electromagnetism class with 176 students enrolled in the "off-term" E\&M course in the TEAL format during Fall 2001. This experimental group was the first to study in the specially designed TEAL space (see Figure 1). The learning materials used in the Fall 2000 pilot study were validated and refined for the Fall 2001 course and included more experiments and visualizations. The first large-scale implementation of the TEAL project was in a freshman electromagnetism class with 514 students enrolled in the "on-term" E\&M course during Spring 2003.

The "on-term" version of the course is usually taken during the Spring semester of the freshman year, with a student enrollment of about 550 to 700 . This group typically consists of about $90 \%$ freshmen, although the rest are upper class students. The "off-term" version, taken during the Fall semester, consists of about 150 students. Typically, two types of students take the off-term course. About one third of this heterogeneous group are freshmen, who, based on excellent achievements in either an Advanced Placement (AP) physics high school course or an MIT internal "qualifying exam", are exempt from the mechanics course, which is usually taught in the Fall term and taken prior to the E\&M course. The other two thirds of the population are mostly sophomores, with some junior or senior students, who are required to repeat the course, mainly due to low grades in the introductory physics courses in prior semesters.

In this study, one experimental group was off-term (Fall 2001, $\mathrm{N}=176$ ) course, while the other experimental group was on-term (Spring 2003, N=514). The control group consisted of 121 students who took the traditional on-term E\&M course in the Spring 2002 semester, which was based on traditional lectures with demonstrations in a large lecture hall and smaller recitation sessions. The control group students were volunteers who were asked to respond to the pre- and posttests for monetary compensation.

All three research groups-the two experimental groups and the control group - studied the same E\&M topics in a similar sequence. Students of all these three groups received feedback on problem sets they had submitted as homework assignments. The experimental group students submitted most of their assignments via the Web and some manually, while the control group students submitted all the assignments manually. The assignments were graded by teaching assistants (TAs) for both the experimental groups and the control group. Although the experimental groups practiced both analytical and conceptual questions (using the PRS), the control group students solved mainly analytical problems.

With respect to faculty, the transition from the small- to the large-scale mode of about 600 students per semester required additional faculty who had not been involved in the early project phases. Moreover, the more homogenous "on-term" stu- 
dent population was different from our first experimental ("off-term") students. We could not foresee differences between these two experimental groups regarding their attitudes toward new teaching methods that required their active participation.

\section{Research Instruments}

The importance of a built-in detailed formative and summative assessment process that accompanies the development and implementation of each stage of the project is vital (Birenbaum, 2003; Black, 1995; Dori \& Tal, 2000; Dori, 2003). Research instruments were selected to best measure students' performance in the social, cognitive, and affective domains. They included conceptual tests, a survey, focus group discussions, and classroom observations, as described in Table 1. In the cognitive domain, pre- and posttests were administered to compare the extent of change among students at various academic levels. The tests included multiple-choice and open-ended questions that required both qualitative and quantitative responses. In the affective domain, we assessed students' attitudes towards studying in the TEAL learning environment and their preferences with respect to the various teaching methods employed in that environment.

In the cognitive domain, pre- and posttests enabled us to compare the extent of conceptual change among students at various academic levels. Both pre- and posttests consisted of 20 multiple-choice conceptual questions from standardized tests (Maloney et al., 2001; Mazur, 1997) augmented by questions of our own devising. The conceptual test was of two types, A and B. These two types contained similar questions with slight variations to avoid the effect of prior exposure in the pretest to questions that would later appear in the posttest. About half of the students responded to type A pretest and then took type B in the posttest. The other half of the students responded to type B pretest and to type A in the posttest. Statistical analysis of the results revealed no significant differences between the two test types.

To illustrate the type of conceptual questions included in the pre- and posttests, Figure 6 shows an example of a conceptual question. This question was part of type A test and had an analogous one in type B. The question concerns Ampere's

TABLE 1

Research Instruments

\begin{tabular}{llll}
\hline Domain & \multicolumn{1}{c}{ Assessed Variable } & \multicolumn{1}{c}{ Instruments } & \multicolumn{1}{c}{ Question Type } \\
\hline Cognitive & $\begin{array}{l}\text { Algorithmic understanding } \\
\text { Conceptual understanding }\end{array}$ & $\begin{array}{l}\text { E\&M standard MIT tests } \\
\text { Pre- and posttests }\end{array}$ & $\begin{array}{l}\text { Algorithmic questions } \\
\text { Conceptual and phenomenon } \\
\text { understanding questions }\end{array}$ \\
Social & Round table discourse & $\begin{array}{l}\text { Classroom observations } \\
\text { SurveyFocus group at } \\
\text { the end of the course }\end{array}$ & $\begin{array}{c}\text { Teaching methods } \\
\text { preferences }\end{array}$ \\
\hline
\end{tabular}

Note. $\quad \mathrm{E} \& \mathrm{M}=$ electricity and magnetism; MIT = Massachusetts Institute of Technology. 


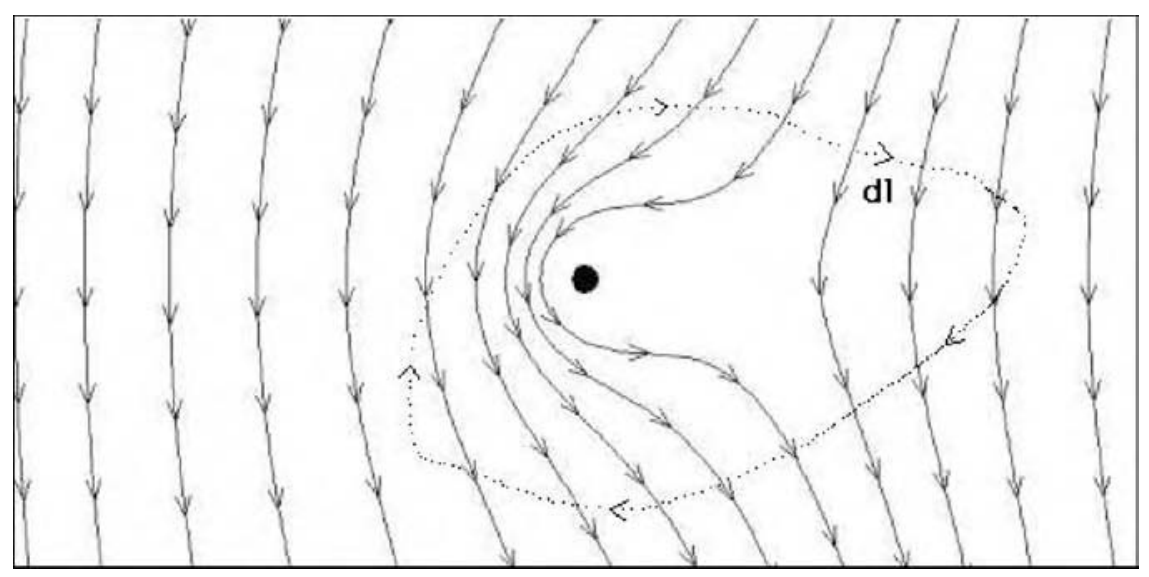

FIGURE 6 An example of a conceptual question. When we evaluate the line integral of the magnetic field dotted into the line element around this closed contour, the result we find is: (a) non-zero and positive, (b) non-zero and negative (the correct response), (c) zero, (d) more information is needed, and (e) indeterminate.

Law, which states that the line integral of the magnetic field around a closed contour must be proportional to the amount of current passing through the open surface enclosed by that contour. The student needs to know that a line integral is non-zero when a current cuts through the surface, as it does here. The sense of the traversal of the contour is indicated by the arrows on the contour (the dotted line). The direction of the field lines near the wire indicates that the current is flowing through the wire out of the page. Therefore, the closed line integral around the contour yields a non-zero and negative quantity.

In the posttest (only) we added to the 20 multiple-choice conceptual questions one open-ended, conceptual question developed by Bagno and Eylon (1997). The question required the student to summarize the main ideas of electromagnetism according to their order of importance without using formulae or equations.

The results of the conceptual pre-and posttests were analyzed using a classification of the students' academic level as reflected in their pretest results. Using the conceptual pretest results we divided the Fall 2001 population into three about equal parts, thereby defining three academic levels: high, intermediate, and low. High academic level students scored above 45 points out of 100, intermediate level students scored between 30 and 44, and low academic level students scored below 30 . These borderlines remained the same for the second experimental group in the Spring 2003, as well as for the control group in Spring 2002.

The open-ended surveys and the focus group discussions were related to the affective domain and pertained to student attitudes towards various teaching meth- 
ods in the TEAL project, including their relative effectiveness. Students who took the course in Fall 2001 and Spring 2003 were asked the following questions:

A. List in descending order the most important elements, which contribute to your understanding of the subject matter taught in the course.

B. Explain why you selected the first, most important element in (A) above.

Question A was scored by assigning 3 points to the most important element, 2 to the second, and 1 to the third. In this article we present findings that are based on observations, pre- and postconceptual tests, and the survey. Analysis of students' responses to open-ended conceptual question and the focus group findings will be presented and discussed elsewhere.

\section{FINDINGS}

Our findings relate first to the social domain - the round table discourse recorded while observing a classroom session in which students carried out the microwave antenna experiment and associated visualizations. Second, we discuss findings in the cognitive domain - students' conceptual understanding, based on the multiple-choice conceptual questions in the pre- and posttests. Then, in the affective domain, we present students' responses to the questions in the open-ended survey.

\section{Social Aspects of Learning: TEAL Round Table Discourse}

We conducted several observations in the TEAL classroom. In this article we report on one of them. The subject taught in the session described below was interference and included the microwave antenna experiment, which was performed by the Spring 2003 students. The students measured the radiation pattern generated by a free-standing spark-gap antenna. They then examined the standing wave set-up when the same antenna was placed in front of a vertical aluminum plate. This standing wave was generated by the interference between the incident and reflected electromagnetic waves. The researcher sat at one of the TEAL space tables and observed three groups of three students each. The first group included the students A (female), G (male), and I (female). The second group consisted of D (male), W (female), and L (male); and the third consisted of R (male), S (female), and $B$ (female).

Analyzing the conversations, we found that students' discourse can be categorized into four types: technical, sensory, affective, and cognitive. The technical category relates to dealing with the equipment and executing instructions for carrying out the experiment. The sensory category relates to comments about sensed phe- 
nomena, like seeing sparks. The affective category includes reactions of joy, frustration, wondering, amazement, etc. Within the cognitive category, we distinguish between question posing, hesitation, knowledge construction, establishing new insights, and sharing knowledge with peers. Question posing and hesitation appear occasionally as sub-categories of categories other than cognitive. At the end of each discourse participant statement, we added in curly braces the pertinent category or categories and where applicable, their sub-categories. Statements in square brackets indicate nonverbal participant description or gestures, as well things that happened in the TEAL classroom.

The professor began the session with an explanation of interference, using PowerPoint slides, visualizations, a demonstration, and some examples from his own research. During the mini lecture some students seemed distracted: they chatted or played with their computers. Few of them started to work on the experiment handouts, although others seemed to be working on assignments for another class. The professor then showed a demonstration of constructive and destructive interference using movable transmitters and a receiver, which was projected on the eight screens surrounding the class. Noise produced while moving the transmitter or receiver indicated the locations of destructive and constructive interference patterns. Some students watched the demonstration, others did not. Following the demonstration, the professor showed a visualization illustrating the waves interfering constructively and destructively. Several students, who had not been following the mini-lecture, clearly paid attention to the visualization. Student D's response to the visualization was: That's really cool! \{affective\}

\section{Professor: I'd like to ask you a PRS question. \{cognitive—question posing\}}

All the students picked up their PRS units. The question was posted; students immediately read the question and raced each other to answer most quickly. Students' numbers appeared on the screen when they responded, so the order of answering was known to the students and the data was recorded into the database to be used for attendance and effort monitoring. Although the professor did not indicate for this to be a competitive exercise, this was clearly a game that had developed at this particular table for answering PRS questions.

Professor: Most people say 2, but not everyone. I'd like you to talk about it in your group. \{encourages cognitive—-knowledge sharing\}

Students discussed the answer and then submitted PRS responses again, this time almost all the students agreed. Lecture continued, building on that PRS question and then the professor showed an example of interference, a demonstration that uses a video camera to get a close up view of soap bubbles. While students 
were watching the soap bubbles projected on the screens around the room, the professor explained how the colors relate to interference patterns.

\section{R: Wow! That's amazing! \{affective\}}

The professor discussed how his own research involves wave interference, and showed slides of how interference can be used in microscopy imaging technology to see inside the biological phenomena. He showed an image of red blood cells.

S: [who had previously been working on a chemistry assignment with $\mathrm{R}$, but is now interested in the lecture and the images being shown]: Wow! that's really cool! \{affective\}

R: Yeah! It is! \{affective\} [A few minutes later, the professor puts up an animated sequence of cell mitosis, $\mathrm{S}$ nudges $\mathrm{R}$ to look at the screen. Both watch the sequence and smile.] \{affective\}

Professor: Ok, now we're going to start the experiment. You all should already have the handout. \{technical\}

$\mathrm{S}$ : Plug in the power supply \{technical\} [reading from handout, then checks that it is plugged in].

B: Turn on the transmitter using on-off switch! \{technical\} [S looks for switch, cannot find it. B finds it and turns it on].

B: Ok, so now we need to get a spark, but I can't see a spark. \{sensory\}

$\mathrm{S}$ : Where are you looking? \{sensory-hesitation\}

B: Right here, same place. \{sensory\}

$\mathrm{S}$ : Ok, fine, fine. \{affective\}

B: [Reading from handout]: That's good. Move the transmitter as far away from the computing equipment as possible. \{affective, technical\}

S: [Reading]: Start with receiver a few centimeters from the transmitter! $\{$ technical\}

S: Whoa! Look at that! Look at that! \{affective\} [Moving receiver toward transmitter and looking at response on meter].

R \& B: Whoa! \{affective\}

R: We're seeing physics. Woohoo! \{sensory, affective\}

$\mathrm{S}$ : Hey, look at this! \{affective, sensory\}

S: Look: parallel, perpendicular\{technical, sensory\} [moving the receiver through different orientations]. That answers question one \{technical\} [writes down answer on handout].

B: Whoa [laughs]. \{affective\}

S: You guys, [reading] so the radiation we're generating is produced by charges oscillating back and forth. [stops reading] So the answer to question one was that when it's parallel, it goes like this, when it's 
perpendicular, like this [gestures with experimental setup]. \{cognitive-construction of knowledge, knowledge sharing\}

B: Yeah, yeah.

A: [reads handout aloud]: Plug in your receiving antennae at the position indicated on the diagram. Plug in the jack on the board. Where is that? \{technical—question posing\}

$\mathrm{G}$ : It's there. \{technical\}

A: Oh. What jack? \{technical—question posing \}

G: This jack. \{technical\}

A: Ooooh! [laughs, reads handout aloud]. Adjust wing nut until you get a spark. Did we get a spark? \{affective, sensory-hesitation

G: When we twist this, when they get closer together, then we should get a spark. \{technical, cognitive - knowledge sharing\}

A: $O h, O K$.

Professor: So do you have transmission? \{technical—question posing

A: Noooo.

I: I see. Try moving this guy closer. \{technical\}

A: Wait... oh wait, I see a spark! Wait now it doesn't spark. \{sensory\}

G: But see now they're touching. \{sensory\}

A: Oh. Where am I looking? \{sensory—question posing\}

Professor: Right in between there. Just go very slowly, very slowly. \{technical\}

A: There it is. \{technical\}

Professor: There we go. So you need to let them get closer together really slowly. \{affective, technical\} [A continues reading handout aloud, the professor moves to another table].

A: What two configurations are they talking about? \{cognitive- question posing?

G: This one right here. The idea is that these charges are moving back and forth. \{cognitive - knowledge sharing\}

A: Right.

G: [making sure A understands]: So, which one is going to generate a greater signal? \{cognitive-question posing\}

A: What is the parallel orientation? \{cognitive - question posing\}

G: We can just call this the parallel orientation and this the orthogonal orientation. \{cognitive - knowledge sharing\}

A: [writing]: So the parallel orientation will generate the biggest signal because? \{cognitive-question posing

I: Because the waves are going through it? \{cognitive-question posing\}

A: How do I say that the... like... waves are going to go through it? \{cognitive-new insight? 
G: Because the E-field is unable to generate current in the orthogonal direction. \{cognitive - new insight, knowledge sharing\}

A: Eh? I don't get it. \{cognitive-question posing\}

G: Electric field only induces current in the parallel orientation. $\{\mathrm{cog}-$ nitive - new insight, knowledge sharing

G: [calls graduate teaching assistant (TA)]: What do they mean by the direction of polarization? \{cognitive-question posing

TA: Basically what they mean is if this is $x, y$ and $z$, then it is polarized along the z-axis. \{cognitive-knowledge sharing\}

G: I don't know how to describe the direction for the electric field. [To TA] How do you describe the direction of the electric field? \{cognitive - knowledge construction, question posing\}

TA: [drawing on the whiteboard.]

G: Can you actually describe the waves in space? I don't understand the question. \{cognitive-question posing\}

A: How do you know that it's going that way? \{cognitive-question posing\}

TA: The antenna is producing the radiation, so it has to be moving away from the antenna. \{cognitive-knowledge sharing\} ...

Professor: [comes over]: What is the electric field at the surface of this plate? \{cognitive - question posing \} [Students thumb through handout]

Professor: Don't look! You know this. \{affective\}

D: We know this? \{cognitive - hesitation\}

Professor: What is the electric field inside the conductor? \{cognitive-question posing

W: Zero. \{cognitive-knowledge construction, sharing\}

Professor: Right. Ok, so what is the parallel electric field right close to the conductor here? \{cognitive-question posing\}

$\mathrm{W}$ : Zero. \{cognitive-knowledge construction, sharing\}

Professor: Why? [pause] because that is the only answer you could give me right? So why is this happening? So let's say it was non-zero. What would the electrons be doing in that sheet? \{cognitive- knowledge sharing, question posing\}

L: Moving around. \{cognitive-knowledge construction, sharing\}

Professor: Right, Exactly! They move around to try and screen out that electric field. So the conductor does everything it can to try to keep the parallel electric field zero. And that's why this acts as a reflector, because it just forces the electric field to be zero here. Why don't you try that? \{affective, cognitive-knowledge sharing\} ... [Tests handed back by TA]

A: I got all of the questions on the test. I've never gotten all of the points on a test before. This is the greatest day of my life. \{affective\} 
D congratulated student A on her performance. The group looked through how they did on the test and did not seem competitive with each other about grades.

Summarizing this round table discourse, it was apparent that the social aspect was an important factor in the construction of knowledge and contributed to establishing new insights and sharing knowledge with peers. The class discourse showed that the TEAL approach encouraged multiple-aspect interactions, which include technical, sensory, affective, and cognitive categories. As the the session progressed the emphasis shifted from technical and sensory aspects to affective and cognitive ones. Mason (2001) argued that by sharing knowledge with peers, confronting different ideas, and being criticized by others, students can check their own knowledge. The transcript presented in this section illustrates an incremental shift in students' cognition from ambiguous, partially constructed knowledge to repaired, shared knowledge (Roschelle, 1992), much of which is gained through visualization, engagement with an experimental setting, and social interaction.

\section{Cognitive Domain: Conceptual Understanding Results}

One of the TEAL project goals was to decrease the students' failure rate in the E\&M course while strengthening their conceptual and analytical understanding. This objective was fully achieved: The failure rates in the two experimental groups were less than $5 \%$ in the small- and large-scale experimental groups, respectively, compared with 13\% in the traditional control group (Spring 2002).

To assess the effect of the pedagogical methods and the technology implemented in the TEAL project, we examined the scores in pre- and posttests that tested conceptual understanding for two experimental groups: Fall 2001 (off-term) and Spring 2003 (large-scale on-term). These two groups were compared to the control group - the traditional E\&M course in Spring 2002 semester. Figures 7 through 9 present the conceptual test results of Fall 2001 small-scale experimental group, Spring 2003 large-scale experimental group, and Spring 2002 control group, respectively.

We found that both TEAL student (experimental) groups improved their conceptual understanding significantly more than the control group. Comparing the three academic levels within these two experimental groups (Figures 7 and 8) and the control group (Figure 9), we found that all three levels improved their scores noticeably in both the experimental and control groups.

Our findings indicate that students who studied in the TEAL format significantly improved their conceptual understanding of the various complex phenomena associated with electromagnetism. The average improvement (net gain) of both the Fall $2001(M=28)$ and Spring $2003(M=37)$ TEAL students from the pretest to the posttest was significantly $(p<0.0001)$ higher than that of the control group of Spring $2002(M=16)$. 


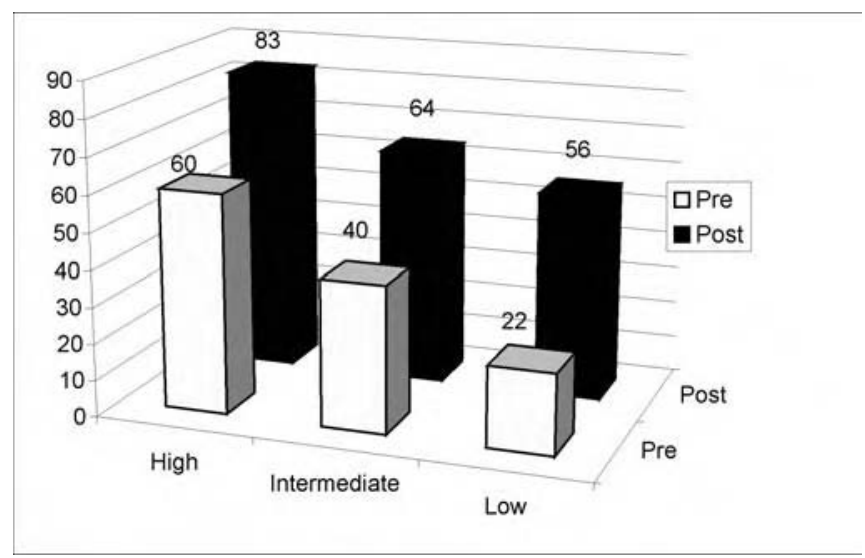

FIGURE 7 Conceptual understanding scores in the pre- and posttests by academic levels for the Fall 2001 TEAL project experimental group $(N=176)$.

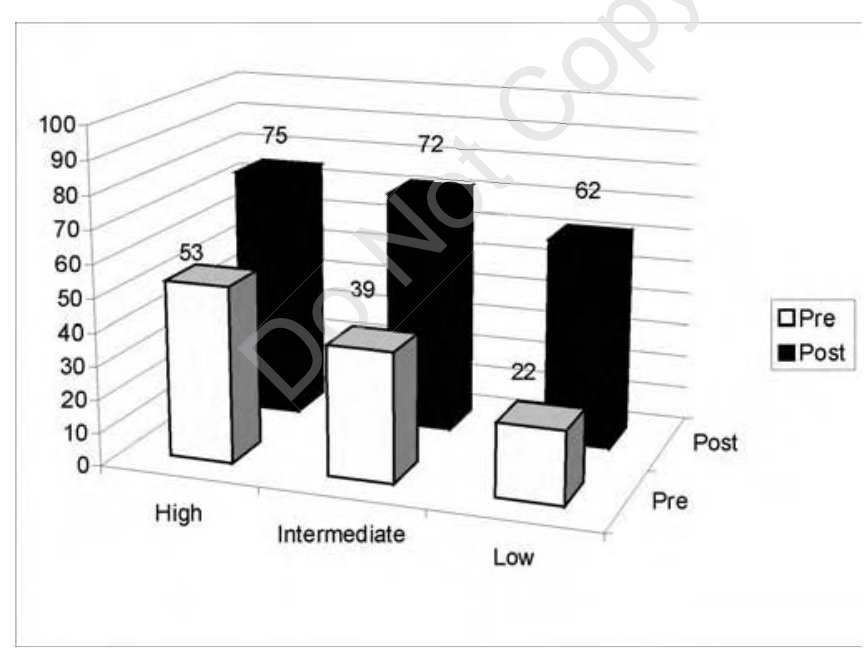

FIGURE 8 Conceptual understanding scores in the pre- and posttests by academic levels for the Fall 2003 full-scale TEAL project experimental group $(N=514)$.

As Figures 7-9 show, the net gain of the low-achieving students was the highest for all three research groups, probably because their starting point was the lowest, so they had the most room for improvement. However, each of the three academic levels of the two experimental groups improved their conceptual understanding to a larger extent than their peers in the control group. For example, the mean scores of the Fall 2001 experimental students who were the high achievers, went up from 


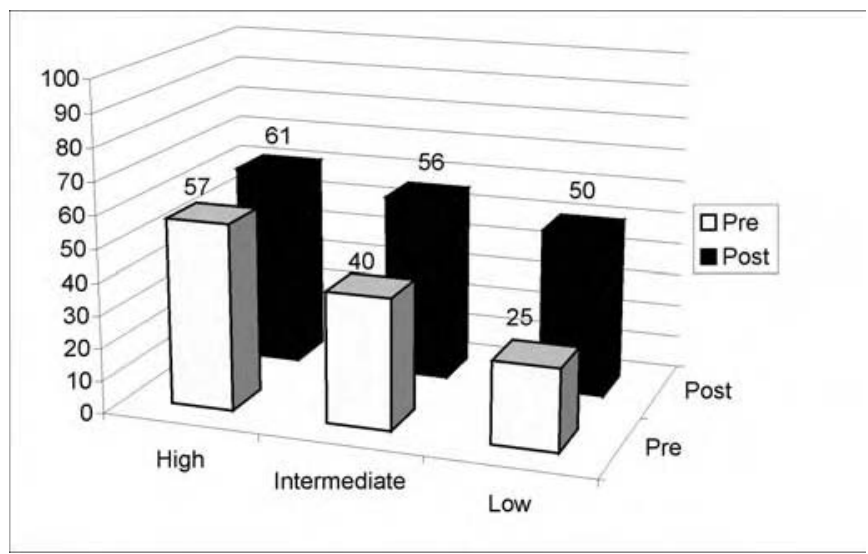

FIGURE 9 Conceptual understanding scores in the pre- and posttests by academic levels for the Spring 2002 traditional course control group $(N=121)$.

60 to 83 , and of Spring 2003-from 53 to 75, although the scores of the high achievers of the Spring 2002 control group, went from 57 only to 61 .

To analyze the effect of TEAL on high achievers, we examined the relative improvement measure $\langle g\rangle$, which is defined as follows according to Hake (1998).

$$
\langle g\rangle=\frac{\% \text { Correct }_{\text {post-test }}-\% \text { Correct }_{\text {pre-test }}}{100-\% \text { Correct }_{\text {pre-test }}}
$$

Table 2 shows the results of comparing the relative improvement of the 2001 and 2003 experimental groups to the 2002 control group. The relative improvement of both experimental groups was significantly $(F=19.2, p<.0001)$ higher than that of the 2002 control group. We then compared separately the relative improvement, $\langle g\rangle$, of students in each academic level of the experimental large-scale (Spring 2003) group with its corresponding level in the control (Spring 2002)

TABLE 2

Relative Improvement of Conceptual Understanding of Fall 2001 and Spring 2003 Experimental Groups Versus the Spring 2002 Control Group Students

\begin{tabular}{|c|c|c|c|c|c|c|}
\hline \multirow[b]{2}{*}{ Group } & \multicolumn{2}{|c|}{ Experimental Fall 2001} & \multicolumn{2}{|c|}{ Experimental Spring 2003} & \multicolumn{2}{|c|}{ Control Spring 2002} \\
\hline & $n$ & $\langle g\rangle$ & $n$ & $\langle g\rangle$ & $n$ & $\langle g\rangle$ \\
\hline Total $(N=811)$ & 176 & 0.46 & 514 & 0.52 & 121 & 0.27 \\
\hline High & 58 & 0.56 & 40 & 0.46 & 19 & 0.13 \\
\hline Intermediate & 48 & 0.39 & 176 & 0.55 & 50 & 0.26 \\
\hline Low & 70 & 0.43 & 298 & 0.51 & 52 & 0.33 \\
\hline
\end{tabular}


group. These two groups were identical both with respect to homogeneity and the proportion (90\%) of freshmen who had not been exposed to E\&M. The comparison results have shown that for each of the three levels - high, intermediate, and low-the difference in relative improvement (Table 2) was significant $(p<.01)$ in favor of the experimental group.

Within the two experimental groups we found no significant difference in the relative improvement of the high achievers, indicating that both the small- and large-scale TEAL groups had a similar effect on high achievers. However, for both intermediate and low achievers, we found a significant difference $(p<.001)$ between the small- and large-scale TEAL groups. In the large-scale (on-term) implementation, the relative improvement of the intermediate and low achievers was better than in the small scale.

To examine the assumption that the TEAL teaching methods and environment are capable of mobilizing students upward across academic levels, we calculated the correlation between large-scale experimental group students' mean scores of the pretest, posttest, and course grade. We found a low $(r=0.17)$ yet significant ( $p$ $<.0001)$ correlation between the pretest mean scores and the course grades and high $(r=0.64)$ and significant $(p<.0001)$ correlation between the posttest mean scores and the course grades. Examining each academic level separately, the correlation between the pretest mean scores and the course grades was low and insignificant, while the correlation between the posttest mean scores and the course grades for each academic level was still high and significant.

These finding indicate that an appropriate learning environment that fosters social constructivism is instrumental in improving the achievements of students at all academic levels. The technology-rich engagement atmosphere and the group interactions enabled the high achievers to blossom while teaching their peers. This setting also facilitated upward mobility of the intermediate and low achievers, thereby reducing failure rate and obtaining overall better results.

\section{Affective Domain: Students' Preferences}

Figure 10 presents experimental students' responses to the survey question regarding the relative importance of the various elements in the course.

We divided the students' responses into four categories: oral explanations in class (mini-lectures), technology, written problems, and textbook. The recommended course textbook was Physics for Scientists and Engineers (Serway \& Beichner, 2000). The technology category included visualizations, desktop experiments, Web-based home assignments, and PRS-induced peer discussion (Mazur, 1997). Written problems included problem sets given as home assignments and analytical problems solved in class. Figure 10 shows that three of the four categories are about equally important, while the role of problem solving is the highest in both experimental groups. 


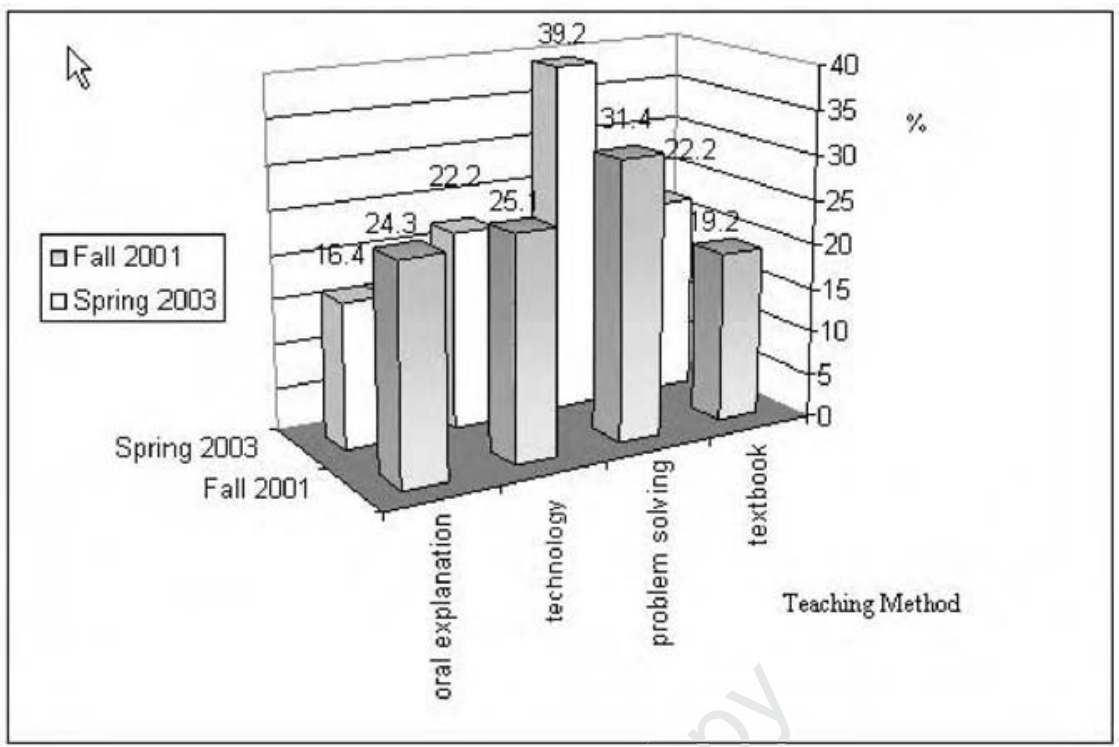

FIGURE 10 The elements that contributed to students' understanding of the subject matter taught in Fall 2001 and Spring 2003.

Students' comments regarding the use of the various educational technology tools helped us understand the reasons for their value from the students' viewpoint. Below are examples of comments of several students, who expressed their opinions on (a) oral explanations (mini-lectures), (b) technology (see students' comments Nos. 2, 3, 5, and 6), (c) written problem solving, and (d) the textbook. These citations represent students' arguments for selecting various categories in Figure 10.

1. Mini-lectures: "I find that the oral explanations in lecture far surpassed the amount of depth in comprehension in comparison with the book. The lectures facilitated the whole learning process for me."

2. Visualization: "Visualizations and conceptual questions help explain what is really happening behind all the numbers, especially in an abstract topic as magnetostatics."

3. Desktop experiments: "Desktop experiments help to really grasp the conceptual background of various problems while integrating calculations and quantitative analysis."

4. Small group interactions: "The group interactions allowed me to ask questions without feeling embarrassed at my lack of knowledge, the group questions created more group interactions." 
5. Web-based home assignments: "On-line assignments are much easier to turn in than conventional problem sets. I don't have to worry about paper, handwriting, dropping it off, or even being out of town when it's due. With these things in mind, it is a pleasure to work on the homework each week. I simply print out the web assignment, work on the problems as I see fit, and type in the answers later. In fact, I've gotten much more out of this work than I expected."

6. PRS: "The PRS questions are awesome! They enhance the material very well and they help to understand the concept a great deal. The immediate feedback allows for correction."

7. Written problems: "I think they are useful because they are actually real problems that apply the things we teach ourselves to situations around us."

8. Textbook: "There's just way too much to study. Between problem sets and lecture slides and experiments and study guides and workshops and PRS questions and reading assignments... I find it easier to just learn from the book than try to wade through that complete mess."

The TEAL project was well received in the small-scale implementation and with reservations in the 2003 large-scale implementation. In the small-scale about $70 \%$ said they would recommend the TEAL course to their peers, although in the large-scale the corresponding percentage was $54 \%$. The 2003 experimental students expressed both positive and negative attitudes in the course survey when asked about the pros and cons of working in teams. Below are two positive and two negative examples.

"The in-class discussions were particularly helpful because people had the opportunity to defend their opinion and try to convince others that they were right. In doing so, I picked up more practical explanations (without use of equations) to problems."

"The 2D/3D simulations gave a real example to see what was going on... even with the forces and things that aren't visible (e-fields, b-fields, etc)."

"Frankly, I don't think the TEAL electromagnetism course should be forced on people. Lecture format is a LOT better for some people, for example me."

“... You can't let the blind lead the blind, and I'm afraid that's exactly what teamwork in physics is... especially when we haven't learned the material individually first."

\section{RESEARCH LIMITATIONS AND STRENGTHS}

The fact that not all the variables of students in the two experimental groups and the control group were identical is a source of several research limitations. Unlike the 
experimental group students, who responded to both conceptual and analytical problems as part of their weekly assignments, the control group students had to solve only analytical problems in their weekly assignments. The only times the control group students were presented with multiple choice conceptual questions were in the pre- and the posttests. The conceptual pre- and posttests administered to the two experimental groups were mandatory, whereas the control group students volunteered to take the pre- and posttests and were compensated for their time. Students in the experimental group were credited for attendance as well as for active participation in desktop experiments and visualizations. Consequently, experimental students' attendance was over $80 \%$ while that of control students was about $50 \%$.

Beside these few weak points, the research features the following strong points.

1. The experimental students consisted of the entire class population, while the volunteers in the control group accounted for about $20 \%$ of their class. The average final grade of the volunteers in the traditional course was higher (66 out of 100 points) than the average score of the rest of the class (59 points). Therefore, significant difference between the experimental and control groups might have been even more accentuated had we used a random sample of the control class.

2. The conceptual pre- and posttests originally included 25 questions administered to both the 2001 and 2003 experimental groups as well as the 2002 control group. However, the professor who taught the Spring 2002 control group asked us to leave out of the comparison five questions that seemed to him too specific to the TEAL setting and its visualization orientation. He justifiably claimed that including these questions would unfairly bias the results in favor of the experimental group. Hence, the results presented in this paper do not include these five questions for any one of the three research groups. In spite of removing these five questions, the results were still highly significant in favor of the TEAL approach.

3. The findings regarding students' conceptual understanding and preferences were consistent across the two experimental cycles of the TEAL project and even improved in the second cycle-the large-scale experiment.

4. The six teachers who taught the various sessions in the large-scale TEAL format were novice in both the active learning approach and the applications of the educational technologies. Nonetheless, experimental students' performance in the conceptual tests as well as in the final course grades were significantly better than those of their control peers even though the professor of the control group was renowned as an excellent lecturer.

\section{DISCUSSION AND FURTHER RESEARCH}

Learning is a social experience in which interaction enables the negotiation of meaning and co-construction of knowledge among students. Indeed, our round ta- 
ble discourse has shown that new meaning is constructed for the group members that would probably not have occurred for one individual alone. Interaction becomes a social mode of thinking in which students learn through engaging in dialogue (Ernest, 1995). The understanding that for students to learn they have to construct knowledge rather than passively absorbed it is one of the important consequences of cognitive science research on education (Tobin \& Tippins, 1993). In TEAL, students were engaged in active learning through the desktop experiments, visualizations, and PRS-induced discussions.

Science educators are facing increasing demands as they are asked to teach more content more effectively and to engage their students in scientific practices (Edelson, 2001). The National Science Education Standards (National Research Council, 1996) expressed strong disapproval of the traditional emphasis on memorization and recitation. They stressed the need to foster conceptual understanding and give to students the firsthand experience of questioning, gathering evidence, and analyzing that resembles authentic scientific processes. Science teachers' conceptions of science and the way they teach it is a result of the way they were taught in their schools (Hewson \& Hewson, 1989). The methods by which science instructors were taught are often inconsistent with contemporary educational approaches (Mellado, 1998). This state of affairs calls for a comprehensive conceptual change in the way science is taught in higher education. Such a change on the part of science faculty requires the development and implementation of new curricula and the adaptation of new teaching and assessment methods that foster conceptual understanding. We applied these guidelines while designing the TEAL space, pedagogy, and learning materials. The TEAL project caters to social constructivism by fostering individual and group thinking, supported by educational technology, and small and large group discussions for knowledge building.

Our study has established that the TEAL format has indeed had a significant and strong positive effect on the learning outcomes of MIT freshmen through technology-enabled active learning. The failure rate, a major trigger for the project, has decreased substantially while the learning gains as measured by standard assessment instruments have almost doubled. The TEAL project incorporated into the classroom a collaborative, active learning approach, enhanced by visualizations, desktop experiments, Web-based assignments, a personal response system, and conceptual questions with peer discussions. These teaching methods, applied within the TEAL framework, enhanced the students' ability to transfer concepts such as electromagnetic field lines and associated phenomena from the abstract level to the concrete one, thereby contributing to better conceptual understanding of these physical phenomena.

Our results indicate that students significantly improved their conceptual understanding of the subject matter. The net gain and relative improvement of TEAL students' conceptual understanding has been found to be significantly higher than that of the control group. In the survey of teaching method preferences, the experi- 
mental students rated written problems, followed by lectures, technology, and textbook. One should bear in mind that in this type of basic physics courses, students traditionally have been accustomed to classes that are made up of passive lectures that closely follow a particular textbook. Moreover, the TEAL project requirements for students' engagement during and after class, which implies attendance, is contrasted with MIT (and other) students' perceptions of "academic freedom," namely absence from classes and studying mainly for passing the final examination. This aspect may also provide partial explanation of some of the students' reservations regarding the TEAL project. One explanation of some negative student attitudes towards the TEAL environment is in line with the ideas presented by Huba and Freed (2000). As they noted, understanding and accepting new roles is more difficult for students especially if other courses are taught within a traditional, teacher-centered paradigm. In the traditional setting they have a set of expectations that is entirely different than the set of expectations and roles in the learner-centered paradigm.

Providing the technology that has the capability to support high levels of interaction does not always guarantee that substantive discussion and collaboration will occur (Clark, 1994; Salomon \& Perkins, 1998). However, this study has shown that when well-designed educational technology is intertwined with social constructivism, improvement in both the cognitive and affective domains can be achieved not only for middle and high school science education, as shown in previous studies (Blumenfeld, Fishman, Krajcik, Marx, \& Soloway, 2000; Dori \& Barak, 2001; Krajcik, Marx, Blumenfeld, Fishman, \& Soloway, 2000; Linn, 1998), but also in undergraduate science education (Dori, Barak \& Adir, 2003) in general and physics education in particular (Dori et al., 2003).

Building on the encouraging assessment results reported here, we plan on expanding the active learning, technology-based components of the TEAL course to the basic undergraduate mechanics course as well.

Referring to the quote of Huba and Fredd (2000) at the beginning of this article, we view the TEAL project as a step towards preparing tomorrow's citizens, leaders, and experts for future roles by engaging them in a technology-enhanced environment that support peer discussion and collaboration.

We plan to study the extent of retention of this course after about one year to see if the TEAL project has a long-term effect on students' retention compared with students who studied E\&M in traditional mode.

\section{ACKNOWLEDGMENTS}

The TEAL project is supported by the d'Arbeloff Fund for Excellence in MIT Education, the MIT/Microsoft iCampus Alliance, National Science Foundation Grant \#9950380, and the MIT School of Science and Department of Physics. 
We thank Steve Lerman, Director, Center for Educational Computing Initiatives (CECI), MIT for hosting and supporting this research. We also thank the faculty, staff, and students of the CECI who contributed to the TEAL project. Special thanks to Erin Hult who helped collecting and processing the assessment data, to Mark Bessette for Figures 1 and 5, and Michael Danziger for Figure 4. Last but not least, thanks to Ayala Cohen of the Faculty of Industrial Engineering and Management, Technion, for her valuable statistical analyses.

\section{REFERENCES}

Bagno, E. \& Eylon, B. (1997). From problem solving to a knowledge structure: An example from the domain of electromagnetism. American Journal of Physics, 65, 728-735.

Beichner, R. (1994). Testing student interpretation of kinematics graphs. American Journal of Physics, $62,750-762$.

Beichner, R. J. (2002). SCALE-UP Project. Retrieved February, 2004, from www.ncsu.edu/per/scaleup.html

Beichner, R., Bernold, L., Burniston, E., Dail, P., Felder, R., Gastineau, J., et al. (1999). Case study of the physics component of an integrated curriculum. American Journal of Physics, 67, S16-S24.

Belcher, J. W., \& Bessette, R. M. (2001). Using 3D animation in teaching introductory electromagnetism. Computer Graphics 35, 18-21.

Belcher, J. W., Olbert, S., \& Bessette, M. (1999). The physics of using field line animation in the teaching of electromagnetism. A poster presented at the American Association of Physics Teachers Meeting, Anaheim, CA.

Belcher, J. W., \& Olbert, S. (2003). Field line motion in classical electromagnetism“ The American Journal of Physics 71, 220-228.

Bevilacqua, F., \& Giannetto, E. (1998). The history of physics and European physics education. In B. J. Fraser \& K. J. Tobin (Eds.), International Handbook of Science Education (pp.1015-1026). Dordrecht, The Netherlands: Kluwer Academic.

Birenbaum, M. (2003). New insights into learning and teaching and their implications for assessment. In M. Segers, F. Dochy, \& E. Cascallar (Eds.). Optimizing New Modes of Assessment: In Search of Qualities and Standards (pp. 13-36). Dordrecht, The Netherlands: Kluwer Academic.

Black, P. (1995). Assessment and feedback in science education. Studies in Educational Evaluation, 21, 257-279.

Blumenfeld, P., Fishman, B. J., Krajcik, J., Marx, R. W., \& Soloway, E. (2000). Creating usable innovations in systemic reform: Scaling up technology-embedded project-based science in urban schools. Educational Psychologist, 35(3), 149-164.

Brasell, H. (1987). The effect of real-time laboratory graphing on learning graphing representations of distance and velocity. Journal of Research in Science Teaching, 24, 385-395.

Bruer, J. T. (1993). Schools for thought. Cambridge, MA: The MIT Press.

Bybee, R. W., \& Ben-Zvi, N. (1998). Science curriculum: Transforming goals to practices. In B. J. Fraser \& K. J. Tobin (Eds.), International Handbook of Science Education (pp. 487-498). Dordrecht, The Netherlands: Kluwer Academic.

Chabay, R. W., \& Sherwood, B. (1995). Electric and Magnetic Interactions. New York: Wiley.

Chabay, R. W., \& Sherwood, B. A. (1996). 3-D visualization of fields. The changing role of physics departments in modern univers ties. Proceedings of the International Conference on Undergraduate Physics Education, AIP Conference Proceedings 399, 763. 
Chabay, R. W., \& Sherwood, B. A. (2000). Matter \& Interactions II: Electric and Magnetic Interactions. Hoboken, NJ: Wiley.

Chi, M. T. H. (1992). Conceptual change within and across ontological categories: Implications for learning and discovery in sciences. In R. N. Giere (Ed.), Cognitive models of science: Minnesota studies in the philosophy of science. Minneapolis, MN: University of Minnesota Press.

Clark, R. E. (1994). Media will never influence learning. Educational Technology, Research and Development, 42(2), 21-29.

Cross, R. C. (1989). Magnetic lines of force and rubber bands. American Journal of Physics, 57, $722-725$.

Cummings, K., Marx, J., Thornton, R., \& Kuhl, D. (1999). Evaluating innovations in studio physics. Physics Educational Research. American Journal of Physics, (Suppl. 67), S38-S45.

Dewey, J., 1924. The School and Society. Chicago: University of Chicago Press.

Dori, Y. J. (2003). From nationwide standardized testing to school-based alternative embedded assessment in Israel: Students' performance in the "Matriculation 2000" Project. Journal of Research in Science Teaching, 40, 34-52.

Dori, Y. J., \& Barak, M. (2001). Virtual and physical molecular modeling: Fostering model perception and spatial understanding. Educational Technology \& Society, 4(1), 61-74. Retrieved February, 2004 from http://ifets.ieee.org/periodical/vol_1_2001/dori.pdf

Dori, Y. J., Barak, M., \& Adir, N. (2003). A Web-based chemistry course as a means to foster freshmen learning. Journal of Chemical Education, 80, 1084-1092.

Dori, Y. J., Belcher, J. W., Bessette, M., Danziger, M., McKinney, A., \& Hult, E. (2003). Technology for active learning. Materials Today, 6(12), 44-49.

Dori, Y. J., \& Tal, R. T. (2000). Formal and informal collaborative projects: engaging in industry with environmental awareness. Science Education, 84, 95-113.

Duit, R., \& Treagust, D. F. (1998). Learning in science-From behaviorism towards social constructivism and beyond. In B. J. Fraser \& K. J. Tobin (Eds.), International Handbook of Science Education (pp. 3-25). Dordrecht, The Netherlands: Kluwer Academic.

Duschl, R. A., \& Hamilton, R. J. (1998). Conceptual change in science and in the learning of science. In B. J. Fraser \& K. J. Tobin (Eds.), International Handbook of Science Education, pp.1047-1065. Dordrecht, The Netherlands: Kluwer Academic.

Edelson, D. C. (2001). Learning-for-use: A framework for the design of technology-supported inquiry activities. Journal of Research in Science Teaching, 38, 355-385.

Ernest, P. (1995). The one and the many. In L. Steffe \& J. Gale (Eds.), Constructivism in education (pp. 459-486). Hillsdale, NJ: Lawrence Erlbaum Associates, Inc.

Eylon, B., \& Ganiel, U. (1990). Macro-micro relationships: the missing link between electrostatics and electrodynamics in students' reasoning. International Journal of Science Education, 12, 79-94.

Furio, C., \& Guisasola, J. (1998). Difficulties in learning the concept of electric field. Science Education, 82, 511-526.

Hake, R. R. (1998). Interactive-engagement versus traditional methods: A six-thousand-students-survey of mechanics test data for introductory physics courses. American Journal of Physics, 66, 67-74.

Hermann, F. (1989). Energy density and stress: A new approach to teaching electromagnetism. American Journal of Physics, 57, 707-714.

Hewson, P. W., \& Hewson, M. G. (1989). Analysis and use of a task for identifying conceptions of teaching science. Journal of Education for Teaching, 15, 191-209.

Huba, M. E., \& Fredd, J. E. (2000). Learner-centered assessment on college campuses. Boston, MA: Allyn \& Bacon.

Inhelder, B., \& Piaget, J. (1958). The growth of logical thinking from childhood to adolescence (A. Parsons \& S. Seagrin, Trans.). New-York: Basic. (Original work published 1995)

Johnson, D. W., Johnson R. T., \& Smith, K. A. (1998). Active learning: Cooperation in the college classroom. Edina: Interaction Book Company. 
Jonassen, D., Carr C., \& Yueh, H. P. (1998). Computers as mindtools for engaging learners in critical thinking. TechTrends, 43(2), 24-32.

Jonassen, D., Davidson, A., Collins, M., Campbell, J., \& Haag, B. B. (1995). Constructivism and computer-mediated communication in distance education. The American Journal of Distance Education, $9(2), 7-26$.

Keyser, M. W. (2000). Active learning and cooperative learning: Understanding the difference and using both styles effectively. Research Strategies, 17, 35-44

King, J., Morrison, P., Morrison, P., \& Pine, J. (1992). ZAP! Freshmen electricity and magnetism using desktop experiments: A progress report. American Journal of Physics, 60(11), 973-978.

Krajcik, J., Marx, R. W., Blumenfeld, P., Fishman, B., \& Soloway, E. (2000, February). Inquiry based science supported by technology: Achievement among urban middle school students. Paper presented at the AERA meeting. Available at: http://www.-personal.umich.edu/'krajcik/AERA.outcomes.pdf

Laws, P. W. (1991). Calculus-based physics without lectures. Physics Today, 44, 24-31.

Laws, P. W., Rosborough, P. J., \& Poodry, F. J. (1999). Women's responses to an activity based introductory physics program. American Journal of Physics, 67, S32-S37.

Linn, M. C. (1998). The impact of technology on science instruction: Historical trends and current opportunities. In B. Fraser \& K. Tobin (Eds.), International handbook of science education (pp. 265-293). Dordrecht, The Netherlands: Kluwer Academic.

Maloney, D. P., O'Kuma, T. L., Hieggelke, C. J., \& Van Heuvelen, A. (2001). Surveying students' conceptual knowledge of electricity and magnetism. American Journal of Physics, 69(Suppl.), S12-S23.

Manhart Barrett, E. A. (2003). Imagery: Experiencing pandimensional awareness. Conference of the Society of Rogerian Scholars, Emerging Pattern in a Changing World, Savannah, Georgia. Retrieved February 8, 2005, from http://medweb.uwcm.ac.uk/martha/barrettpaper.htm

Mason, L. (2001). Introducing talk and writing for conceptual change: A classroom study. Learning and Instruction, 11, 305-329.

Mathewson, J. H. (1999). Visual-spatial thinking: An aspect of science overlooked by educators. Science Education, 83, 33-54.

Mazur, A. (1997). Peer Instruction. Upper Saddle River, NJ: Prentice Hall.

McDermott, L. C. (1991). Millikan lecture 1990: What we teach and what is learned -Closing the gap. American Journal of Physics, 59, 301-315.

McDermott, L. C., \& Shaffer, P. S. (1992). Research as a guide for curriculum development: An example from introductory electricity. Part 1: Investigation of student understanding. American Journal of Physics, 60, 994-1013.

McDermott, L. C., Shaffer, P. S., \& the Physics Education Group. (2002). Tutorials in introductory physics. Upper Saddle River, NJ: Prentice Hall.

Mellado, V. (1998). Preservice teachers' classroom practice and their conceptions of the nautre of science. In B. J. Fraser \& K. G. Tobin (Eds.), International handbook of science education (pp. 1093-1110).

Miller, A. I. (1984). Imagery in scientific thought: Creating 20th century physics. Boston: Birkhauser.

Niemi, H. (2002). Active learning-A cultural change needed in teacher education and schools. Teaching and Teacher Education, 18, 763-780.

O'Malley, J. (1999). Students perception of distance learning, online learning and traditional classroom. Journal of Distance Learning Administration, 2(4).

Perkins, D. N. (1992). Smart schools—From training memories to training minds. New York: Free Press.

Roschelle, J. (1992). Learning by collaborating: Convergent conceptual change. Journal of the Learning Sciences, 2, 235-276. 
Scheker, H. P. (1998). Integration of experimenting and modeling by advanced educational technology: Examples from nuclear physics. In B. J. Fraser \& K. J. Tobin (Eds.), International Handbook of Science Education (pp. 383-398). Dordrecht, The Netherlands: Kluwer Academic.

Schank, R. (1993/1994). Goal-based scenarios: A radical look at education. Journal of the Learning Sciences, 3, 429-453.

Serway, R.A., \& Beichner, R.J., (2000). Physics for scientists and engineers with modern physics (5th ed., Vol. 2.). Australia: Thomson Learning, Inc.

Simpson, T. K. (1997). Figures of thought: A study of Maxwell's Treatise. Santa Fe, NM: Green Lion Press.

Slotta, J. D., \& Chi, M. T. H. (1996). Understanding constraint-based processes: A precursor to conceptual change in physics. Paper presented at the Eighteenth Annual Conference of the Cognitive Science Society, La Jolla, California: Lawrence Erlbaum Associates, Inc.

Sokoloff, D. R., Thornton, R. K., \& Laws, P. W. (1999). Real time physics active learning laboratories. New York: Wiley.

Salomon, G., \& Perkins, D. N. (1998). Individual and social aspects of learning. Retrieved February 8, 2005, from http://construct.haifa.ac.il/ gsalomon/indsoc.htm

Salomon, G., Perkins, D. N., \& Globerson, T. (1991). Partners in cognition: Extending human intelligence with intelligent technologies. Educational Researcher, 20(4), 2-9.

Strike, K. A., \& Posner G. J. (1985). A conceptual change views of learning and understanding. In L. H. T. West \& A. L. Pines (Eds.), Cognitive structure and conceptual change. New York: Academic.

Towns, M. H., \& Grant, E. R. (1997). "I believe I will go out of this class actually knowing something": Cooperative learning activities in physical chemistry. Journal of Research in Science Teaching, 34(8), 819-835.

Thacker, B. A., Ganiel, U., \& Boys, D. (1999). Macroscopic phenomena and microscopic processes: Student understanding of transients in direct current electric circuits. American Journal of Physics, 67, S25-S31.

Thornton, R. K. (1992). Enhancing and evaluating students' learning of motion concepts. In A. Tiberghing \& H. Mandel (Eds.), Physics and learning environments (pp. 265-283). Berlin, Germany: Springer Verlag.

Thornton, R. K., \& Sokoloff, D. R. (1990). Learning motion concepts using real-time microcomputer-based laboratory tools. American Journal of Physics, 58, 858-866.

Tobin, K., \& Tippins, D. (1993). Constructivism as a referent for teaching and learning. In K. Tobin (Ed.), The practice of constructivism in science education (pp. 23-38). Washington, DC: AAAS Press.

Viereck, G. S. (1929). What life means to Einstein: An interview by George Sylvester Viereck. The Saturday Evening Post, October 26.

Vygotsky, L. S. (1963). Thought and language. Cambridge, MA: MIT Press. (Translation of Russian original, published 1934)

Vygotsky, L. S. (1978). Mind in society. Cambridge, MA: Harvard University Press.

von Glaserfeld, E. (1987) The construction of knowledge: Contributions to conceptual semantics. Seaside, CA: Intersystems Publications.

White, B. (1993). ThinkerTools: Causal models, conceptual change, and science education. Cognition and Instruction, 10, 91-100. 